\title{
MDO Evaluation in California: History, Review, and Discussion
}

\author{
Paul Jenkins \\ National University, La Jolla, California, USA \\ Email: pjenkins@nu.edu
}

How to cite this paper: Jenkins, P. (2020). MDO Evaluation in California: History, Review, and Discussion. Psychology, 11, 679-691.

https://doi.org/10.4236/psych.2020.115046

Received: April 15, 2020

Accepted: May 16, 2020

Published: May 19, 2020

Copyright $\odot 2020$ by author(s) and Scientific Research Publishing Inc. This work is licensed under the Creative Commons Attribution International License (CC BY 4.0).

http://creativecommons.org/licenses/by/4.0/ (c) (i) Open Access

\begin{abstract}
In 1986 the state of California enacted the Mentally Disordered Offender law. Its purpose is to protect society from certain inmates with dangerous but treatable severe mental disorders, and to provide treatment for those inmates in the most appropriate setting. The designation has significant consequences for inmates, including often being initially paroled to a state hospital, rather that straight to the community. This paper describes the MDO certification process and explores some of the related professional, ethical, and moral issues related to the MDO process. The paper concludes that the intention and basic framework of the MDO program are sensible and morally justifiable, however, it is also appropriate and necessary to reconsider the factors that are assessed in the process, how those factors are assessed, and how that information is used.
\end{abstract}

\section{Keywords}

Assessment, Mentally Disordered Offender, Forensic

\section{Background}

Many societies have to deal with the challenge of differentiating those behaviors which break the rules of their society and call for punishment of the offender, as opposed to behavior which reflects a disturbed mind, and thus calls for mental health treatment or at least criminal leniency. In most societies, there are separate systems addressing mental health and criminality. This has the potential for working well when individuals exhibit either mental health problems or criminality, but presents a challenge when an individual exhibits both. This is particularly difficult when the symptoms of mental illness are an important factor in the commission of criminal behavior or are severe enough to require a high level of treatment. The co-occurrence of mental illness and criminality had led to 
many points of contact between the two fields. These contact points exist in many places, including the insanity defense, the concept of diminished capacity, competency to stand trial, diversion programs, sentencing considerations, treatment while incarcerated, readiness for parole, reentry planning, and services offered or required upon parole. This is not a complete list, and each is a fascinating topic of exploration in itself. For the purposes of this paper, however, we are going to look at a single contact point.

That point is the Mentally Disordered Offender (MDO) program that exists in California. The MDO law was enacted by the California Legislature in 1986. It is codified under Penal Code 2960. The law has two primary purposes, to protect society from prisoners who have dangerous, but treatable severe mental disorders, and to provide treatment for those prisoners (Shouse California Law Group, 2016). Treatment and secure housing are provided by the California Department of Corrections and Rehabilitation (CDCR) and the Department of State Hospitals (DSH). Both departments maintain secure facilities for these prisoners that both protect the public and provide a setting for mental health treatment. California law requires that every inmate receives a mental health evaluation within a year of their first year of incarceration. This evaluation then becomes the basis for initial treatment and referral for a thorough assessment of the inmate's possible qualification for MDO status. The qualification requires that the inmate meets all of six criterion: 1) the inmate has committed a qualifying, violent crime, 2) the inmate has a qualifying, severe mental disorder, 3) the inmate's mental disorder was the cause of, or at least a significant factor in the crime, 4) the inmate has received treatment in prison for at least 90 days, 5) the inmate is not in full remission from the disorder or cannot be kept in remission without treatment, and 6) the inmate represents a substantial danger of physical harm to other people because of his/her disorder. After the initial assessment, if the inmate has been found to meet all criterions for MDO status, he or she must be recertified every year (Board of Parole Hearings, 2016).

A vital condition of MDO status is that it requires that the inmate continues to receive mental health treatment, as an involuntary inpatient, until he or she no longer meets the criterion for that status, or can be safely treated on an outpatient basis. What this means, in practice, is that if an MDO inmate reaches the end of their determinate sentencing (a specific amount of time, designated by the courts, for incarceration for a particular crime) and still requires inpatient treatment, he or she may be kept in a locked facility within the CDCR or DSH until they are deemed safe to be treated on an outpatient basis and released to the community. This raises a number of criminological, psychological, and ethical questions. For instance, there is the fundamental human rights issue of whether it is ever okay to hold a prisoner longer than the sentence assigned by the original court. Second, and if it is okay, under what circumstances? How can a person be properly assessed to determine those circumstances? And finally, how those circumstances can be changed, so that a person can and should be released? While it is beyond the purview of this paper to fully explore all of these 
issues, it is important to note that they are all present. In regard to the first and second, taken together in the context of the MDO program, the question is whether it is okay to hold people in custody beyond their assigned sentence if their mental disorder makes them an ongoing public safety risk.

This issue used to be considered under the label of "criminally insane", however it is important to differentiate MDO from criminal insanity. Historically, the concept referred to anyone who was deemed by society to be insane and committed a crime as a result of that insanity. Currently, criminally insane refers to people who have committed crimes (typically quite violent ones) who have been found not guilty by reason of insanity, or to be unfit to stand trial. They are too violent and dangerous to be let go, so they are involuntarily committed to mental hospitals and can be kept there as long as they are still considered "sick" and "dangerous". MDO status individuals are different in that they have been convicted of a crime in a court of law, but it is deemed that their mental illness was a significant factor in the commission of violence, and thus they should be treated for their mental illness and it should continue to be considered as a determining factor in placement and parole decisions.

To better understand the program, we need to examine the six determining criteria.

1) Does the inmate have a severe mental disorder.

2) Did the inmate commit a violent crime.

3) Did the severe mental disorder cause the crime.

4) Is the mental disorder in remission and can it be kept in remission.

5) Has the inmate been receiving treatment for the disorder.

6) Is the inmate still at risk to be violent because of the disorder.

Much can be said about each one, but I will make only a few comments about each. In regard to the first, there is a definition of severe mental disorder which reads, "an illness or disease or condition that substantially impairs the person's thought, perception of reality, emotional process, or judgment; or which grossly impairs behavior; or that demonstrates evidence of an acute brain syndrome for which prompt remission, in the absence of treatment, is unlikely" (Board of Parole Hearings, 2016). The approved list of mental disorders notably does not include personality disorders, adjustment disorders, epilepsy, mental retardation, other developmental disabilities, or substance abuse. This is interesting as many people would assume correctly that personality disorders (especially Antisocial Personality Disorder) and substance use disorders (especially alcohol abuse) are mental disorders and could be shown to be strongly related to violent crime (Schug \& Fradella, 2015).

In regard to the second, there is also a specific list of crimes which can be considered, and naturally almost all of them include elements of violence, such as Assault with a Deadly Weapon. There are others that are more difficult to evaluate as qualifying, such as vandalism, trespassing, or DUI, when there is violence involved. Even more tricky is the fact that the offence does not have to involve actual violence, but includes threats or even implied threats of violence. 
There was a case where the defendant had broken into an unoccupied building in the middle of the night and accidently started a fire. The violent crime criterion was found to be met, by a number of evaluators, because the fire that was set could have spread to other buildings where people could have been hurt. Many people would find this stretches the definition of a violent crime.

The third criterion is even more difficult to evaluate. The question of how an inmate's mental disorder impacted the commission of a crime is often difficult to answer. In some cases, of course, it is easy. A person, in a delusional state, decides that their small children are possessed by the devil, and need to be killed to free them from the possession and protect the killer from their influence. In many other cases, the question is more difficult. The crime may be a "typical", criminally oriented offence, such as robbery. To what extent, if any does the person's mental illness impact criminal activity, primarily motivated by a desire for money, sex, revenge, or other factor associated with criminality, but not necessarily mental illness? This question is further complicated when, 1) there are no records available that address the mental state of the offender, 2) the inmate claims that he was not experiencing symptoms of mental illness at the time of the crime, 3) the inmate claims that he does not remember the incident, or denies he was guilty, 4) the symptoms of mental illness may have been a very small factor, or simply exacerbated other factors, such as substance abuse or homelessness.

The fourth criterion actually involves two factors, the level of remission of the inmate's mental illness, and their ability to maintain that remission in a less controlled environment, namely being on parole in the community. Remission is an interesting concept. It refers to the reduction or outright elimination of symptoms related to a mental disorder. As with many concepts in mental health, it is more complicated than it may seem on the surface. For instance, symptoms of a mental disorder tend to wax and wane over the course of time. How much often depends on what mental disorder is being considered. Schizophrenia, for instance has such profound natural changes in the presence of symptoms that we think in terms of phases of the disease, including the prodromal, active, and residual. Another difficulty is the fact that many mental illnesses are unlikely to "go away" entirely, with no symptoms whatsoever. Often, there is not full agreement on what constitutes optimal outcome in mental illness, and what can be best hoped for is a significant level of improvement in overall functioning (Kennedy, 2002). Part of the challenge in MDO evaluation is that the criterion is stated as "remission", with few specific guidelines for what is an adequate level of remission. The only one provided is that remission needs to have been present for at least a year. However, this guideline is rather arbitrary and often difficult to assess. For instance, if an inmate has been moved multiple times over the last year, not only should this be expected to effect their level of remission as they adjust to a new setting, but often results in poor records regarding level of remission, especially from institutions that may not specialize in providing mental health service. This is not to impugn the treatment of prisoners within CDCR, 
but just to point out the obviously non-optimum situation of trying to successfully treat the symptoms of severe mental illness under the conditions of even the most clinically oriented and well-run prison setting.

The other part of the remission criterion involves the ability of the inmate to remain in remission without treatment. Please note, the concept of "treatment" means within a highly-controlled setting in prison or a state hospital. The challenge is to assess how likely it is that the inmate would successfully remain in remission and not be a physical threat to others. This is very subjective in nature, with a number of factors to consider, and is, finally a judgment call. There are no specific, truly objective criterion to measure to reach a decision. Certainly, some of the main ones to consider are the inmate's recent history of violence and compliance with treatment, his motivation to continue his treatment, and his support in the community to be able to maintain his connection to and participation with treatment resources.

The fifth criterion is relatively straightforward. It regards the inmate's recent receipt of services. He must have been receiving mental health treatment for at least 90 days. This treatment needs to be post-conviction, and can include inpatient treatment within the Department of State Hospitals (DSH), the Department of County Hospitals, the California Department of Corrections and Rehabilitation (CDCR), or a Parole Outpatient Clinic.

The sixth criterion is an assessment of overall dangerousness. The question is whether the inmates' ongoing mental illness leads them to represent a substantial danger of physical harm to others. This question is answered by addressing six primary factors: history of violence, prior performance on supervised release, compliance with treatment, insight, remission, and environmental risk. The first factor has the strongest empirical support (Schug \& Fradella, 2015). A history of violence is the best know predictor of future violence. It is much more questionable how strong the rest of the factors are. A poor history of performance on supervised release could easily be connected to either generally low functioning (can't hold a job or maintain housing) or criminality (prone to get needs met in antisocial ways). Empirically based studies (Harris, et al., 2015) have found that insight and remission are actually not strongly associated with assaultiveness on the part of released inmates with mental illness.

The results of the assessment of these six areas are then tabulated in numerical form, with a zero if the inmate did not meet the criterion and the number of the criterion if he did. For instance, if the inmate met criterion one, two, five, and six, but not three or four then the conclusion would be noted as 120,056. For the overall assessment to be positive, the inmate needs to meet all six criterions. Not meeting any of the six means that the overall conclusion is negative, that the inmate should not be certified as MDO.

It is important to note that inmates being considered for MDO status receive multiple assessments. The inmate is initially assessed by two doctors, one from CDCR and one from DSH. If the two assessments disagree (one finds the inmate positive on all six criterion and the other does not) then Difference of Opinion 
(DOP) exists, and two independent evaluators (not employees of CDCR or DSH) are brought in to break the tie. If the evaluators do not find the inmate qualifies for MDO status, he is referred to an outpatient treatment clinic upon parole. If they do, the inmate may be sent to a DSH institution for further treatment, or they may be paroled to the community, depending on the findings from the assessments and the conclusion of the Board of Parole Hearings.

\section{Some Areas of Challenge in This Process}

1) The fundamental right of the state to detain people for extended periods of time based on a risk of possible future violence.

2) The issue of assessing dangerousness:

a) The problem of connecting the risk of future violence with the presence of severe mental illness.

b) The problem of assessing certain criterion with an adequate level of reliability, objectivity, or validity.

c) Deciding what mental disorders should qualify, especially regarding personality disorders and substance abuse.

3) The difficulty and expense of treating severe mental disorders in a prison environment.

1) To begin, there are two major points to consider. The first is that there is not nearly enough room in this paper to do justice (sic) to the issue of the right of the state to engage in preventive detention. It is an issue of such moral, philosophical, and legal depth and complexity that we can do nothing more here than introduce it with a few preliminary observations. Second, although there are issues regarding the appropriateness of detention to avoid future violence, the general appropriateness and goals of the MDO program are supportable. I can be concluded that it is a fundamentally good thing that society identifies and helps inmates who experience symptoms of severe mental illness, and it is a good thing that as society takes measures to protect itself from violence, and sometimes that means that individuals should be detained who are particularly dangerous.

Having introduced those two caveats, we need to further the discussion by pointing out that those goods must always be balanced with other goods, including the fundamental right to freedom and non-coercion, and desire, especially in what we call a "free society" to be given "the benefit of the doubt". In other words, our power-based institutions should always ere on the side of individual freedom, because of the risk of abuse based on the disparity of power between institutions and the individual, a risk and fear that is well-founded historically. This is the foundation of the Western legal principle of being assumed innocent until proven guilty, and it was developed for good reason. Well-meaning folks who become frustrated and upset about protections given those accused (and even convicted) of crimes may not have given enough thought to the ramifications for society if we were, for instance, to reverse the protection principle and assume the accused to be guilty and require that they prove their innocence. 
The resulting dystopian police state would likely horrify those who now enjoy the protections of a "liberal" justice system without appreciating them.

As the previous paragraph makes clear, it is important to consider that no goods or rights exist in a vacuum, unaffected by and therefore limited by other goods or rights. For instance, my right to do what I want with my personal property can easily run against your right not be killed by another if I dump toxins on my property that will leach into the groundwater and kill you if you drink it or eat plants grown with it. This is why a famous adage says, "your right to swing your fist reaches just as far as the end of my nose" (this quotation is often attributed to Oliver Wendell Holmes, but its origins are actually unclear and has been attributed to many famous Americans, including John Finch, John Stuart Mill, and even Abraham Lincoln). The point is that rights and values must always be balanced against other rights and values. For a much more thorough discussion of this issue, I invite you to read Alan Dershowitz (2005) or John Ely (1980), who are both experts on judicial theory and clearly recognize the moral and philosophical challenges inherent in the process of balancing differing interests, values, desires, and rights in a free society.

The more specific and practical question then is, how dangerous does someone need to be in order to preventively restrict their freedom, when otherwise they would be let go? Very few people would disagree with the idea that if it could be ascertained, with $100 \%$ certainty, that a person was about to kill an innocent victim, that it is moral and proper that the person be detained. This position purposely sidesteps the issue of other strategies being implemented to protect the potential victim. Obviously, other things can and should be done, including warning the person, offering them protection, etc. The question is not whether preventive detention is the only possibility, but whether it is one of the proper ones. In a casual, non-institutional context, this is not seriously questioned. During a drunken bar fight, it is perfectly appropriate for people to "hold back" an attacker. The appropriateness of this preventive detention becomes much trickier when, 1) the detaining power is a large, governmental institution like the justice system, and 2) there are serious questions about the validity and reliability of our current assessment system. Thus, a justice system which expands its focus from holding people responsible for acts already committed, to preventive measures to avoid possible future acts should have a very high bar indeed. To justify the continued detention (whether we call it hospitalization or not) of an individual based on the possibility of future offence, there must be valid and reliable (very high likelihood) empirical evidence to support such action.

2) It is this high bar concept that leads to a number of other issues. A primary one regards how well we can assess future dangerousness. This issue is explored in an interesting way in the movie Minority Report (2002), where the premise is that certain people have the "special power" of prescience and thus can "see" a crime taking place before it actually happens, thus allowing the police to arrest the perpetrator before they commit the offence. In the real world, of course, it is not that easy or clear-cut. In fact, assessing future violent recidivism is quite 
challenging. As with assessment of any future behavior, the conclusions are conditional and imprecise, often leading to questionable utility for decision making. If we say that there is a $50 \%$ chance that someone will be violent in the future, this leaves open the questions about future contingencies that would lower or raise the risk (treatment vs. escalating substance abuse), whether or not this individual is in the $50 \%$ that will or the $50 \%$ that won't reoffend, and whether the restrictive and expensive measures being contemplated are or are not worth that risk. What you generally get with actuarial risk assessment is not a particular number, but placement within a set of wide and vague categories (low, medium, and high risk), and this lack of specificity makes it difficult to make important decisions regarding placement and services, especially if those decisions are going to have a profound impact on someone's life and freedom.

The previous section focused on actuarial approaches to risk assessment. This is the application of mathematical and statistical analysis to the likelihood of various future events, based on the known current factors or aspects of the situation. This is different than what is typically referred to as clinical assessment, which uses interviews and/or psychological testing to help reach conclusions about psychological dynamics, diagnosis, and subsequent risk of engaging in various behaviors. Many psychologists rely heavily on this approach, but multiple studies (reviewed in Harris, et al., 2015) have found that clinical judgment, based on direct, clinical interviewing, is less reliable and valid than actuarial risk assessment. The problem is that, despite its superiority to clinical assessment, the use of actuarial assessment is still not very robust in its predictive power (reviewed in Harris, et al., 2015). The focus of the MDO assessment is future risk of violence. Few would question the idea that decision making regarding release on parole should, in part, be based on dangerousness. After all, the entire point of maintaining secure placement and ongoing treatment is protecting society. But if we can't professionally provide a specific, valid, and reliable measure of risk, it does raise the question of the appropriateness of using such an assessment to make life-changing decisions, such on the principle of preventive incarceration.

Another issue related to the need for a high bar of validity and reliability in our risk assessment is the appropriateness of the required areas of MDO evaluation. Do they make sense in drawing conclusions regarding the potential dangerousness of an inmate? The main factors utilized in MDO assessment of risk can be boiled down to, a) the presence of a severe mental disorder and related remission, b) history of violence and prior performance on supervised release, c) insight and compliance with treatment.

In regard to the first, we need to take a closer look at the connection between mental illness and violent criminality. The general public tends to believe that people with severe mental illness are dangerous. In a 2006 national survey (cited in Harvard Mental Health Letter, 2011), 60\% of respondents believed that people with Schizophrenia were likely to be violent, and $32 \%$ believed that people with major depression were likely to be violent. These fears are grossly exaggerated and are driven by many factors, including misleading media representations of 
mental illness (Corrigan, 2005; Wahl, 1995). The reality is actually much more complicated than typically thought (Schug \& Fradella, 2015). For instance, contrary to what many mental health professionals like to believe, there is a link between mental illness and violence (Swanson, Holzer, Ganju, \& Jono, 1990). However, the overwhelming majority of people with psychiatric illness are not violent (Stuart \& Arboldeda-Florez, 2001; Lamberg, 1988), more than two-thirds of violent offenders do not have a mental illness (James \& Glaze, 2006; Skeem, Manchack, \& Peterson, 2010), offenders with mental illness are a heterogeneous group, many of whose offending behavior may be related to other criminogenic factors other than their mental illness (i.e. youth, maleness, poverty, substance abuse, deviant peers, childhood abuse and neglect, etc.), and to the extent that mental illness impacts violent tendencies the connection is weak, the threat is small, and the connection is often indirect and complex (Solomon, Cavanough, \& Gelles, 2005). In fact, Nilsson et al. (2011) and others have found that inmates with a severe mental disorder are less likely to recidivate than inmates without a mental disorder. Harris, et al (2015), discussed research findings that found recidivism of mentally ill offenders ranging from $16 \%$ for those with Schizophrenia to $77 \%$ for those who are psychopathic. In other words, focusing on severe mental illness (especially acute disorders over personality characteristics) as a strong risk factor for violent reoffending is not supported in the literature and is probably associated with cultural myths more than reality.

As a corollary to this idea that there is really a very weak link between mental illness and violent criminality, it follows that it would not be accurate to identify such clinical issues as insight, cooperation with treatment, or remission as important factors in risk assessment. If the presence of a mental illness is itself not a highly important factor in violent crime (5\% according to Frazel \& Grann, 2006), then whether or not it is in remission, how much insight the inmate has about it, and how cooperative he is in treatment are all very minor factors.

Further complicating this issue is the question of which mental illnesses should be included as qualifiers for MDO status. As noted before, according to the statute, a "severe mental illness" is defined as "a disease or condition that substantially impairs thought, perception of reality, emotional process, or judgment; or which grossly impairs behavior; or that demonstrates evidence of an acute brain syndrome for which prompt remission, the absence of treatment, is unlikely" (Board of Parole Hearings, 2016). Currently, most DSM 5 disorders related to psychosis and mood are included. Some of the most commonly diagnosed (from my experience) are Schizophrenia, Schizoaffective, and Bipolar Disorder. Expressly disallowed for MDO status are substance use disorders, developmental disorders, and personality disorders. This is interesting since all three of these diagnostic areas meet the core criterion set out by the statute. They are conditions that impair thought, perceptions of reality, emotional, or judgment. They certainly are all unlikely to spontaneously remit without treatment. It is also true that severe substance abuse and certain personality disorders (antisocial and narcissistic) are strongly correlated with violent reoffending (Nils- 
son, et al., 2011; Schug \& Fradella, 2015). In fact, the research of Nilsson and a number of others (reviewed in Schug \& Fradella, 2015) has found that substance abuse and antisocial personality disorder are much stronger predictors of future violent reoffending than psychotic or mood disorders. It turns out that the presence of a psychotic disorder (treated or not) actually lowers the actuarial risk of violent reoffending below the level of parolees with no diagnosis of a mental disorder. This suggests that the presence of a psychotic disorder could be considered a protective factor for violent reoffending, not a risk factor. The research evidence suggests that if any mental disorders should be considered risk factors for violent reoffending, they should be substance use disorders and personality disorders.

The question then becomes, what are the most important factors in violent recidivism for inmates with severe mental illness? Well, it turns out that the strongest factors are the same for this population as for any other population of violent offenders (Harris, et. al., 2015; Nilsson, et. al., 2011). These factors include age of first conviction, number of prison convictions, history of violence, having a diagnosable personality disorder (especially antisocial), a history of substance abuse, and being diagnosable with conduct disorder in childhood.

3) One of the main issues in our discussion is the question of whether prison is the best venue to provide treatment for individuals who have been found to commit acts of violence as a result of their mental illness. First of all, there is the cost. According to the Legislative Analyst's Office (2017), it costs an average of 71 thousand dollars a year to incarcerate a prisoner in California. That amount does not include the additional costs of mental health care, including EOP placement, Crisis Mental Health Bed placement, providing individual cells, providing psychiatric care, providing psychosocial counseling, and providing the MDO assessment and parole board services. The total cost for an MDO inmate is likely closer to 100 thousand dollars a year. Aside from the problem of the high cost of incarceration, there is the question of whether being incarcerated helps or hinders recovery from severe mental illness. By their nature, prisons are stressful places to live. They are not designed to be comfortable, pleasant places to be. Given the nature of the people who are incarcerated, they can often be hostile, if not outright dangerous places to live. Under the best of circumstances, there is significant lack of freedom of movement, limits to personal decision-making, limits to contact or communication with loved ones, and often limits to treatment/recovery services. This is not to impugn prisons, they are designed to protect the public and punish wrongdoing, and while rehabilitation is also a goal of incarceration, prisons typically focus more on education and job training than mental health services. It is also difficult in most prisons to provide a flexible, stepped system of care that would be optimal for such clients. For instance, a community-based, residential facility can provide a range of services that increases the client's independence (and lowers costs) as the client demonstrates the ability to successfully manage their behavior responsibly. Moving from fully secure, to day passes, to overnight passes, to outpatient care, to after- 
care, based on the clients functional/recovery level, as well as their legal requirements of course, provides a basis for more clinically effective treatment. While some prisons are able to provide substantial mental health services, others, are not set up to do so, and provide little else beyond psychotropic medication in typical prison housing setting. Such conditions are not optimal for treatment and may actually impede the inmate's recovery, thus lengthening his incarceration and adding to the cost to society.

\section{Conclusion}

It is hard to avoid a sense of ambivalence in the exploration of this topic. On the one hand, there are many criminal offenders who have significant mental health problems, troubles which are a major factor in their illegal and sometimes violent behavior. It can be argued that society has both a moral and a practical responsibility to provide treatment for their mental health problems, and make reasonable efforts to protect society from future violence. On the other hand, society also has a moral and philosophical responsibility to avoid unwarranted individual confinement (loss of freedom) and punishment for misbehavior that people have not done yet (basic injustice). There is a core principle in the American education system which says that students should always be placed in the least restrictive environment that still meets their needs. This is based on the idea that children do not voluntarily choose to be in school, they are forced to by their parents and society, therefore, it is humane and just to not put them in an educational placement that is any more restrictive than necessary. There is an argument to be made that the same principle is true for our justice system, despite the obvious differences between the two systems. Why restrict human freedom any more than necessary to "do the job"? That begs the question of just what the job is? The simple answer is that criminal confinement serves three main purposes, 1) protection of society, 2) punishment of the offender, 3) rehabilitation of the offender. The question of how long and under what conditions an offender should be held in confinement can (and should) be a subject for ongoing debate, but reasonable people can agree that the value of human freedom must be balanced against the legitimate need for public safety, and that the effectiveness of rehabilitation can strongly impact the appropriate level and length of both protection and punishment. Effective treatment can lower the level of control and length of time required for incarceration, and thus constitutes best practice as well as providing significant cost savings to society. It is important to approach this debate (best practice for mentally ill offenders with a history of violence) thoughtfully in regard to the MDO program in California. While the intention and basic framework of the MDO program makes sense, and is morally and ethically appropriate, it would be wise (and just) to reconsider the factors that are assessed in the process, how those factors are assessed, and how that information is used to make decisions about placement and services for these offenders. To focus on a few basic points, the research points us in the direction of, 1) de-emphasizing the role of mental illness in assessment of future dangerous- 
ness, 2) to the extent mental illness is considered, include substance abuse and personality disorders as stronger predictors of violence than psychotic or mood disorders, and 3) to reconsider the central role of highly restrictive placement (state prison or state hospital) in the treatment of mentally disordered offenders, especially given what we know about successful mental health treatment, the expenses associated with lengthy and highly restrictive placement, and the moral implications of preventive incarceration.

\section{Conflicts of Interest}

The authors declare no conflicts of interest regarding the publication of this paper.

\section{References}

Board of Parole Hearings (2016). Mentally Disordered Offender Evaluator Handbook for Penal Section 2962.

Corrigan, P. W. (2005). On the Stigma of Mental Illness. Washington DC: American Psychological Association. https://doi.org/10.1037/10887-001

Dershowitz, A. (2005). Rights from Wrongs: A Secular Theory of the Origin of Rights. Cambridge, MA: Basic Books.

Ely, J. (1980). Democracy and Distrust: A Theory of Judicial Review. Cambridge, MA: Harvard University Press. https://doi.org/10.2307/j.ctv102bj77

Frazel, S., \& Grann, M. (2006). The Population Impact of Severe Mental Illness on Violent Crime. American Journal of Psychiatry, 163, 1397-1403.

https://doi.org/10.1176/ajp.2006.163.8.1397

Harris, G. T., Rice, M. E., Quinsey, V. L., \& Cormeir, C. A. (2015). Violent Offenders: Appraising and Managing Risk (3rd ed.). Washington DC: American Psychological Association. https://doi.org/10.1037/14572-000

Harvard Mental Health Letter (2011). Mental Health and Violence. Cambridge, MA: Harvard Medical School.

http://www.health.harvard.edu/newsletters/Harvard_Mental_Health_Letter/2011/Janu ary/mental-illness-and-violence

James, D. J., \& Glaze, L. E. (2006). Mental Health Problems of Prison and Jail Inmates. Washington DC: U.S. Department of Justice, Bureau of Justice Statistics. https://doi.org/10.1037/e557002006-001

Lamberg, L. (1988). Mental Illness and Violent Acts: Protecting the Patient and the Public. JAMA: The Journal of the American Medical Association, 280, 407-408. https://doi.org/10.1001/jama.280.5.407-JMN0805-3-1

Legislative Analyst's Office (2017). How Much Does It Cost to Incarcerate an Inmate. http://www.lao.ca.gov/PolicyAreas/CJ/6 cj inmatecost

Nilsson, T., Wallinius, M., Gustavson, C., Anckarsater, H., \& Kerekes, N. (2011). Violent Recidivism: A Long-Term Follow-Up Study of Mentally Disordered Offenders. PLoS ONE, 6, e25768. https://doi.org/10.1371/journal.pone.0025768

Schug, R. A., \& Fradella, H. F. (2015). Mental Illness and Crime. Thousand Oaks, CA: Sage Publications.

Shouse California Law Group (2016). Mentally Disordered Offenders and California Parole. http://www.shouselaw.com/mdo.html 
Skeem, J. L., Manchak, S., \& Peterson, J. K. (2010). Correctional Policy for Offenders with Mental Illness: Creating a New Paradigm for Recidivism Reduction. Law and Human Behavior, 35, 110-126. https://doi.org/10.1007/s10979-010-9223-7

Solomon, P. L., Cavanaught, M. M., \& Gelles, R. J. (2005). Family Violence among Adults with Severe Mental Illness. Trauma, Violence, and Abuse, 6, 40-54. https://doi.org/10.1177/1524838004272464

Stuart, H. L., \& Arboleda-Florez, J. E. (2001). A Public Health Perspective on Violent Offences among Persons with Mental Illness. Psychiatric Services, 52, 654-659. https://doi.org/10.1176/appi.ps.52.5.654

Swanson, J. W., Holzer, C. E., III, Ganju, V. K., \& Jono, R. T. (1990). Violence and Psychiatric Disorder in the Community: Evidence from the Epidemiological Catchment Area Surveys. Hospital and Community Psychiatry, 41, 761-770. https://doi.org/10.1176/ps.41.7.761

Wahl, O. F. (1995). Media Madness: Public Images of Mental Illness. New Brunswick, NJ: Rutgers University Press. 